TAS Journal, vol. 4, n. 1, p. 27-37

ISSN 2595-1521

MARCH 2020

vsgomide@gmail.com

\title{
Síntese e caracterização do compósito zircônia/alumina para aplicação em próteses
}

\author{
Gomide VS* \\ * Pontifícia Universidade Católica de Minas Gerais, Departamento de Engenharia mecânica.
}

Resumo. A necessidade de se reparar ou reconstruir tecidos ósseos faz com que sejam desenvolvidos biomateriais com aplicações biomédicas para proporcionar melhor qualidade de vida as pessoas que necessitam recorrer à substituição de tais tecidos ou tratamento. Para a seleção do material a ser utilizado, é necessário avaliar alguns fatores fundamentais como: resistência mecânica e biocompatibilidade. Muitas vezes, apenas um material não possui todas as propriedades desejadas, sendo necessária a formação de compósitos, a fim de se garantir as características adequadas. $O$ presente trabalho traz as propriedades mecânicas de um compósito cerâmico zircônia/alumina desenvolvido para aplicação em próteses; a citotoxicidade em fibroblastos humanos foi ensaiada in vitro. Também foram feitos ensaios de resistência à compressão, microdureza, tenacidade à fratura e medida do tamanho de partículas.

Palavras chaves. Zirconia/alumina, próteses, biomateriais, caracterização.

\begin{abstract}
The need to repair or reconstruct bone tissues drives the development to biomedical applications by providing better life quality for people who need to resort to the replacement of tissues. For the selection of the material to be used, it is necessary to evaluate some fundamental factors such as: mechanical resistance and biocompatibility. Often, only one material does not have all the desired properties, requiring the formation of composites in order to guarantee the appropriate characteristics. The present work presents the mechanical properties of a ceramic zirconia/alumina composite developed for application as prostheses; cytotoxicity in human fibroblasts was tested in vitro. Compressive strength, microhardness, fracture toughness and particle size measurements were also performed.
\end{abstract}

Keywords. Zirconia/alumina, protheses, biomaterials, characterization.

Introdução. $\mathrm{O}$ corpo humano pode perder parcialmente ou, até mesmo, totalmente suas funções devido às doenças degenerativas ou acidentes. Além de identificar as causas do problema, é necessário que uma ação corretiva seja tomada para recuperar a função perdida para que o paciente volte a ter uma vida normal. No entanto, quando não é possível recuperar o elemento responsável pela perda de função, é preciso tentar substituí-lo utilizando assim os biomateriais.(1) 
TAS Journal, vol. 4, n. 1, p. 27-37

ISSN 2595-1521

MARCH 2020

vsgomide@gmail.com

O corpo humano pode perder parcialmente ou, até mesmo, totalmente suas funções devido às doenças degenerativas ou acidentes. Além de identificar as causas do problema, o ultrassom e a ressonância indicam regiões onde é necessário ação corretiva para recuperar a função perdida para que o paciente volte a ter uma vida normal. No entanto, quando não é possível recuperar o elemento responsável pela perda de função, é preciso tentar substituí-lo utilizando assim os biomateriais.(1) O desgaste natural do corpo humano é resultado do envelhecimento e suas consequências são nítidas. O corpo humano perde grande parte de sua capacidade motora; alguns órgãos não desempenham mais satisfatoriamente suas funções e os ossos se tornam frágeis. $\mathrm{O}$ desenvolvimento contínuo dos biomateriais tem possibilitado cada vez mais a melhoria da qualidade de vida e o bem-estar da população. Estes materiais são empregados com o objetivo de reconstrução de tecidos e órgãos que tenham sofrido dano ou apresentem falha. Tendo em vista a necessidade de melhoria da saúde geral dos brasileiros, grande parte dos biomateriais usados no Brasil é importada, o que acaba por gerar gastos elevados por parte do Sistema Único de Saúde (SUS) e da Previdência Social.(2)

Durante muitos anos, principalmente em tempos de guerra onde problemas envolvendo perda de membros eram frequentes, os médicos e estudiosos da área buscaram encontrar soluções para substituir ou reparar regiões do corpo humano atingidas por avarias durante a vida. Com isto, o uso de materiais metálicos, resinas acrílicas e implantes autógenos apresentavam graves problemas devido a reações adversas do organismo que rejeitavam o corpo estranho.(3)

Os biomateriais podem ser de origem natural ou artificial utilizados na medicina para fabricação de próteses, implantes ou sistemas que interagirão com o organismo humano.(4) $\mathrm{O}$ corpo humano pode perder parcialmente ou, até mesmo, totalmente suas funções devido às doenças degenerativas ou acidentes. A ressonância magnética e tomografia computadorizada são técnicas utilizadas de análises clínicas com a finalidade de identificar as causas que levaram à perda das funções. Além de identificar as causas do problema, é necessário que uma ação corretiva seja tomada para recuperar a função perdida para que o paciente volte a ter uma vida normal. No entanto, quando não é possível recuperar o elemento responsável pela perda de função, é preciso tentar substituí-lo utilizando assim os biomateriais.(1) Os Biomateriais tem a finalidade é substituir, reconstruir e tratar perdas teciduais, além de recuperar funções comprometidas, sejam elas causadas por doenças, acidentes, ou até mesmo, de nascença.(4)

As cerâmicas utilizadas como biomaterias, possuem propriedades mecânicas aceitáveis para reparação de ossos. As biocerâmicas de baixa densidade e alta porosidade aceleram a recuperação do tecido removido ou danificado. Isso ocorre devido à porosidade, de tamanho controlado, favorecer a adesão do tecido aos poros. Outros tipos de biocerâmicas são as de alta densidade, que geralmente são produzidas com baixa porosidade para garantir maior resistência mecânica.(5) A alumina possui baixa condutividade elétrica, o que a torna um excelente isolante elétrico, e alto ponto de fusão $\left(2050^{\circ} \mathrm{C}\right)$, o que torna difícil conformá-la em uma variedade de formas de acordo com o que se deseja.(6)

A zircônia é o elemento que tem despertado maior interesse aos pesquisadores, devido a sua boa estabilidade química, resistência mecânica, dureza e um módulo de elasticidade da mesma magnitude do aço inoxidável.(7) A zircônia pode apresentar três formas polimórficas (monoclínica, tetragonal e cúbica) a diferentes temperaturas. Estas estruturas possuem diferentes 
TAS Journal, vol. 4, n. 1, p. 27-37

ISSN 2595-1521

MARCH 2020

vsgomide@gmail.com

propriedades mecânicas e podem ser estabilizadas a diferentes temperaturas por meio da adição de óxidos metálicos.(8)

Outro material de alta densidade é a alumina, que possui boa resistência à corrosão, boa biocompatibilidade, alta resistência mecânica à compressão e baixa condutividade elétrica, o que a torna um excelente isolante elétrico, e alto ponto de fusão $\left(2050^{\circ} \mathrm{C}\right)$, o que torna difícil conformála em uma variedade de formas de acordo com o que se deseja.(6) A determinação da fase da alumina a ser utilizada, varia de acordo com a finalidade pretendida. As fases alfa, beta e gama são as que apresentam maior aplicação prática para implantes.(9)

Este artigo traz o desenvolvimento de cerâmicas de Alumina/Zircônia para ser testado como biomateriais. Foram desenvolvidos corpos de prova para os ensaios mecânicos. Ainda, este trabalho aborda a pesquisa biológica, no sentido de testes in vitro da biocompatibilidade da cerâmica com fibroblastos humanos.

Metodologia. Para a realização dos experimentos, foi necessário desenvolver experimentalmente uma biocerâmica para diversos ensaios e testes. $\mathrm{O}$ material proposto e utilizado foi constituído de alumina e zircônia. A biocerâmica utilizada para os ensaios têm a seguinte composição: $50 \%$ em massa de alumina e $50 \%$ em massa de zircônia. Para esta pesquisa foram realizados a preparação da barbotina seguido de testes mecânicos e biológicos (testes in vitro).

Após serem obtidas as amostras, foram realizados diversos experimentos das propriedades físicas e mecânicas, granulometria e também a avaliação da citotoxicidade frente a fibroblastos humanos.

Pós cerâmicos. Os corpos de provas foram preparados utilizando as biocerâmicas de alumina/zircônia inicialmente em forma de pó.

A alumina e a zircônia utilizadas neste trabalho foram fornecidas pelo fabricante Magnesita.

Procedimentos. Os procedimentos tiveram as seguintes etapas: 1) preparação da barbotina; 2) moagem da barbotina em um moinho de bolas; 3) desaglomeração da barbotina; 4) secagem do material; 5) conformação dos corpos de prova utilizando uma prensa uniaxial; 6) sinterização; 7) preparação das amostras através de polimento.

Preparação da barbotina. A preparação da barbotina consistiu em: adição de água e álcool ao pó para promover a suspensão dos óxidos para serem cominuídas em moinho de bolas. Durante a preparação da barbotina foi adicionado o defloculante. Esse aditivo possibilitou a homogeneização das partículas da suspensão durante o processo de moagem dos materiais.(10)

A estabilidade da suspensão foi determinada pelas forças de atração e repulsão entre as partículas. Isso acontece quando as forças de atração são menores do que as forças de repulsão. Os defloculantes elevam a força de repulsão contribuindo para a estabilidade da suspensão e sua homogeneidade. (10)

As propriedades da barbotina dependem da interação entre os seus constituintes (matriz cerâmica, solventes e aditivos). Para o sucesso, é importante que sejam controlados os seguintes parâmetros: tamanho médio de partícula, distribuição no meio, área superficial e o nível de impurezas. 
TAS Journal, vol. 4, n. 1, p. 27-37

ISSN 2595-1521

MARCH 2020

vsgomide@gmail.com

Durante a preparação da barbotina, foi feita uma mistura de 50 gramas de zircônia e 50 gramas de alumina, para a formação do compósito alumina-zircônia. Para completar o volume adequado, foi adicionado $400 \mathrm{ml}$ álcool etílico $70 \%$. O defloculante utilizado foi bicarbonato de sódio (3 gramas). Essa mistura foi colocada em um recipiente de capacidade de $1000 \mathrm{ml}$, contendo $600 \mathrm{~g}$ de bolas de alumina. Esse procedimento de preparação de barbotina também foi desenvolvido por.(11)

Moagem em moinho de bolas. A moagem das amostras foi realizada em um moinho de bolas disponível nos laboratórios da PUC-Minas de Engenharia Mecânica. O material foi submetido a um processo diário de até doze horas durante seis dias.

Desaglomeração. O processo de desaglomeração do pó foi iniciado com um processo de moagem da barbotina em um moinho de bolas. O material foi moído durante um período de aproximadamente 72 horas. Este processo visa homogenizar e diminuir o tamanho das partículas da amostra.

Secagem dos pós. Após o processo de moagem do material no moinho de bolas, a amostra, em forma de barbotina, foi separada das bolas de alumina e colocada em um béquer. Com a utilização de uma mufla, disponível no laboratório de minérios da PUC-Minas localizado no campus do Coração Eucarístico, um processo de secagem da barbotina foi realizado. Este processo de secagem foi realizado em aproximadamente 24 horas a uma temperatura constante de $105^{\circ} \mathrm{C}$.

Processamento dos pós cerâmicos. Após a secagem do material na mufla, o pó cerâmico foi moído em um almofariz com um pistilo a fim de homogeneizar novamente o material.

Corpos de prova. Foi utilizada uma prensa uniaxial para obtenção das amostras.

Para a compactação do pó, foi utilizado um molde metálico. Neste molde, foi aplicado uma pressão uniaxial que fez com que o pó assumisse a configuração do molde. Para este trabalho, foi utilizado um molde cilíndrico de aço inox 310 com cavidade de $18 \mathrm{~mm}$ de diâmetro e $500 \mathrm{~mm}$ de profundidade segundo a norma ASTM C773-88 (ASTM, 2000).

Para criar uma padronização nas amostras, foram pesadas quantidades iguais do pó de alumina/zircônia. As amostras padrões foram de 5 e 10 gramas. As amostras de 10 gramas foram utilizadas para ensaios mecânicos de compressão e compressão diametral; as amostras de 5 gramas foram utilizadas para a análise de microscopia eletrônica de varredura e o ensaio de Arquimedes. Para a compressão do material, foi utilizado uma prensa hidráulica de operação manual com capacidade de até 15 toneladas. A operação foi realizada utilizando uma pressão de 2 toneladas aplicadas por um período de 2 minutos. 
TAS Journal, vol. 4, n. 1, p. 27-37

ISSN 2595-1521

MARCH 2020

vsgomide@gmail.com

Sinterização. O processo de sinterização do material foi realizado no laboratório de tratamentos térmicos da PUC Minas em uma temperatura de $1200^{\circ} \mathrm{C}$ em um tempo de 3 horas. Esta temperatura é a temperatura limite do forno utilizado.

Preparação das amostras. Para a realização da análise microestrutural, as amostras foram preparadas de acordo com as etapas a seguir. As amostras foram embutidas a quente com baquelite da marca Arotec.

Posteriormente, foi realizado o polimento mecanicamente na sequência descrita a seguir: 1) polimento com lixas de granulometrias de 220,360, 400, 600, 800, 1000 e 1200; polimento com suspensão de diamante de granulometrias: $6 \mu \mathrm{m}, 3 \mu \mathrm{m}$ e $1 \mu \mathrm{m}$ - procedimento realizado em politrix da marca Arotec.

Caracterização dos pós cerâmicos. Para caracterizar a microestrutura das amostras geradas durante o experimento, foi utilizada a Microscopia Eletrônica de Varredura - em microscópio eletrônico de varredura, modelo JSM- IT300LV. Esta operação tem como objetivo avaliar e estudar a macroestrutura das amostras e de fratura, conforme a norma NBR 13818. (ABNT, 1997).

Como o material não é um bom condutor de corrente elétrica, foi necessário metalizar a superfície da amostra, utilizando um metalizador modelo S150B Sputter Coater. Na metalização do material foi utilizado a sublimação de ouro em vácuo.

Caracterização da microestrutura e propriedades. Para a determinação da microestrutura e das propriedades mecânicas das amostras, foram realizados ensaios de compressão, compressão diametral, teste de absorção de água, e medida de tamanho de poro.

Ensaios Biológicos. A fim de se avaliar a viabilidade da implantação do compósito em pessoas, foram realizados ensaios in vitro na PUC de Brasília, onde foram observadas as características biológicas do material em um ambiente controlado de laboratório. A resposta biológica à presença do material, podem ser simulados nos ensaios, reduzindo o custo e aumentando a reprodutibilidade do processo em contrapartida aos ensaios in vivo. Através desses testes, é possível simular condições semelhantes às de um organismo vivo, alcançando resultados próximos à realidade.

Os ensaios in vitro foram realizados em culturas de células com amostras de células-tronco mesenquimais, preparadas a fim de se realizar os testes de citotoxicidade para verificar se o compósito será prejudicial as células ou não. Células-tronco mesenquimais possuem semelhanças com fibroblastos, células que formam tecidos de animais. As células são cultivadas isoladas in vitro na tentativa de se controlar sua diferenciação em tecido que dão origem aos ossos.

Esterilização das amostras. As amostras foram esterilizadas por irradiação de 30 KGrays por 30 minutos. A irradiação foi feita na Comissão Nacional de Energia Nuclear (CNEN - UFMG).

Obtenção dos fibroblastos. As próteses desse trabalho foram implantadas em tecidos ósseos cuja estrutura foi comprometida por fatores diversos. Para o reestabelecimento das funções do indivíduo, a prótese será integrada ao tecido, funcionando como uma matriz para o 
TAS Journal, vol. 4, n. 1, p. 27-37

ISSN 2595-1521

MARCH 2020

vsgomide@gmail.com

desenvolvimento de novas células, reestabelecendo suas funções. Para a análise in vitro da biocompatibilidade do compósito com o organismo humano, é necessário o cultivo de células apropriadas, no caso fibroblastos. Fibroblastos, células morfologicamente semelhantes a célulastronco, são células responsáveis pela produção e manutenção da matriz extracelular. Os fibroblastos podem ser obtidos a partir de técnicas de explantes, onde uma parte de um tecido é extraído, lavado com soro físiológico, degradado por meio enzimático ou mecânico e colocado em meios de cultura suplementados com nutrientes propícios para o crescimento e desenvolvimento das células. Após determinado tempo de cultivo, geralmente, apenas os fibroblastos são as células que proliferaram e sobrevivem - teste realizado na PUC-Brasília.

Ensaio de MTT. Para determinar a citotoxicidade de agentes medicinais potenciais e de outros materiais tóxicos foi realizado o Ensaio de MTT. O ensaio de captação do corante tetrazolium (MTT) tem capacidade de avaliar a metabolização deste sal pela ação de enzimas mitocondriais. Este substrato é um composto hidrossolúvel com coloração amarelo-pálido, facilmente incorporado pelas células viáveis, que pela ação da enzima desidrogenase succinica é reduzido formando cristais. Esses cristais possuem coloração azul escuro e são insolúveis em água, permanecendo armazenados no citoplasma celular. Essa solução é colada em uma placa com poços onde é mensurada colorimetricamente com o auxílio do espectrofotômetro em 500 a 600 nanômetros. A formação dessa cor é diretamente proporcional com a atividade de enzimas, portanto pode-se concluir que quanto mais cor é gerada, mais células existem.

As linhagens celulares foram cultivadas em meio de cultura em uma placa de 24 poços numa densidade de $5 \times 10^{4}$ células por poço e incubadas por 18 horas a $37^{\circ} \mathrm{C}$ em estufa com $5 \%$ de $\mathrm{CO}_{2} \cdot(12)$

Análise dos resultados. Microscópio eletrônica de varredura MEV A utilização do MEV, ou microscópio eletrônico de varredura, foi necessária para caracterizar a microestrutura das amostras obtidas. A análise foi dividida em duas etapas 1) a região superficial do material; 2) a região de fratura.

A primeira análise registrou a região superficial nas pastilhas seguindo uma ampliação respectiva de 500 e 2000 vezes. Para a análise de porosidade, foram medidos 5 tamanhos de pó, utilizando meios computacionais provenientes do próprio aparelho. Os resultados observados neste experimento foram satisfatórios, os poros tem volume médio de $1.9224 \mu \mathrm{m}^{3}$.

Para a realização da segunda análise micrográfica da amostra, foi necessário realizar uma fratura no material. A segunda etapa da análise foi realizada em uma região fratura nas pastilhas seguindo uma ampliação respectiva de 500 e 2000 vezes. Na ampliação de 2000 vezes também foi realizado uma análise de porosidade. Os resultados observados neste experimento foram satisfatórios, a região interna do material apresentou uma porosidade média de $7.7262 \mu \mathrm{m}^{3}$.

Como é possível observar, houve um menor valor do tamanho de poros quando observada a região interna do material, ou região da fratura, em comparação a região superficial da amostra. Este fenômeno evidência que o material tem uma maior densidade interna em relação a densidade superficial, isto se deve ao fato do processamento cerâmico que foi realizado desde o processo de 
compactação do pó até o processo de sinterização. Como o material tratado é uma biocerâmica utilizada para próteses, é desejável que o mesmo tenha uma baixa porosidade, pois o material, quando utilizado como substituto ósseo, requer que haja um desenvolvimento celular na superfície do mesmo. Porosidades menores podem ser obtidas através de um período maior de moagem.

Compressão e compressão diametral. Para os testes de compressão, tanto diametral como compressão normal, foram usadas amostras anteriormente feitas com um formato cilíndrico. Foram selecionadas quatro amostras, sendo duas para cada tipo de teste. A tabela 6 mostra os valores de diâmetro e de altura das amostras.

Tabela 6: Valores de geometria das amostras.

\begin{tabular}{|c|c|c|}
\hline $\begin{array}{c}\text { Amostras para a análise de } \\
\text { compressão }\end{array}$ & Diâmetro (mm) & Altura (mm) \\
\hline $\mathbf{1}$ & 19,94 & 13,73 \\
\hline $\mathbf{2}$ & 19,95 & 14,16 \\
\hline $\begin{array}{c}\text { Amostras para o teste de } \\
\text { compressão diametral }\end{array}$ & Diâmetro (mm) & Altura (mm) \\
\hline $\mathbf{1}$ & 19,95 & 13,67 \\
\hline $\mathbf{2}$ & 20,10 & 13,66 \\
\hline
\end{tabular}

Para analisar o comportamento da amostra em um teste de compressão simples, será utilizada a equação 1, utilizando a força máxima do material na pré-ruptura e a área da amostra como uma circunferência de diâmetro previamente medido. Os valores das forças aplicadas para fratura, ou a força máxima e média antes da ruptura, das áreas e das tensões máximas e médias encontram-se na tabela 7 .

$$
\sigma_{C}=\frac{F}{A}
$$

Onde:

$\sigma_{c}=$ tensão de resistência à compressão

$\mathrm{F}=$ força aplicada para a fratura

$\mathrm{A}=$ área da seção transversal da amostra

Tabela 7: Valores de forças, áreas e tensões das amostras.

\begin{tabular}{|c|c|c|c|}
\hline $\begin{array}{r}\text { Amostras para a } \\
\text { análise de compressão }\end{array}$ & Força (kN) & Área (mm $\mathbf{( m o}^{\mathbf{2}}$ & Tensão (MPa) \\
\hline $\mathbf{1}$ & 2,44 & 312,28 & 7,81 \\
\hline $\mathbf{2}$ & 5,44 & 312,59 & 17,40 \\
\hline Média & 3,94 & 312,44 & 12,61 \\
\hline
\end{tabular}


Portanto, o valor médio de resistência a compressão do material é de 12,61 MPa.

Para analisar o comportamento da amostra em um teste de compressão diametral, será utilizada a equação 2 , utilizando a força máxima do material pré-ruptura, a altura e o diâmetro previamente medidos. Os valores das forças aplicadas para fratura, ou a força máxima e média antes da ruptura, das áreas e das tensões máximas e médias encontradas durante o ensaio estão na tabela 8 .

Onde:

$$
\sigma_{t}=\frac{1,6 \times F}{\pi \times d \times h}
$$

$\sigma_{t}=$ tensão de resistência à tração

$\mathrm{F}=$ força aplicada para a fratura

$\mathrm{d}=$ diâmetro da amostra

$\mathrm{h}=$ altura da amostra

Tabela 8: Valores de forças, alturas, diâmetros e tensões das amostras.

\begin{tabular}{|c|c|c|c|c|}
\hline $\begin{array}{c}\text { Amostras } \\
\text { para a análise de } \\
\text { compressão }\end{array}$ & Força (kN) & Altura (mm) & $\begin{array}{c}\text { Diâmetro } \\
(\mathbf{m m})\end{array}$ & $\begin{array}{c}\text { Tensão } \\
\text { (MPa) }\end{array}$ \\
\hline $\mathbf{1}$ & 4,10 & 13,67 & 19,95 & 7,66 \\
\hline $\mathbf{2}$ & 0,5 & 13,66 & 20,10 & 0,93 \\
\hline Média & 2,3 & 13,665 & 20,03 & 4,22 \\
\hline
\end{tabular}

Portanto, o valor médio de resistência a compressão diametral do material é de 4,22 Mpa um pouco menos resistente que o osso humano, mas não tratando de ossos que recebem pressão, como o crânio, esses materiais se mostraram adequados.

Ensaio de Arquimedes. O ensaio de absorção de água, ou também chamado de Ensaio de Arquimedes, foi realizado utilizando 7 amostras. Para o cálculo do valor de absorção de água, em porcentagem, foi utilizado a equação 3. Os valores encontrados estão na tabela 9.

$$
A a=\left(\frac{M u-M s}{M s}\right) * 100
$$

Ms: massa do corpo de prova seco [g]

$\mathrm{Mu}$ : massa do corpo de prova úmido [g]

Aa: absorção de água [\%] 
TAS Journal, vol. 4, n. 1, p. 27-37

ISSN 2595-1521

MARCH 2020

vsgomide@gmail.com

Tabela 9: Tabela ensaio de Arquimedes.

\begin{tabular}{|c|c|c|c|}
\hline Amostras & Amostra seca (g) & $\begin{array}{c}\text { Amostra } \\
\text { submersa (g) }\end{array}$ & Absorção (\%) \\
\hline $\mathbf{1}$ & 4,67 & 5,60 & 19,91 \\
\hline $\mathbf{2}$ & 4,61 & 5,58 & 21,04 \\
\hline $\mathbf{3}$ & 4,72 & 5,67 & 20,13 \\
\hline $\mathbf{4}$ & 4,53 & 5,45 & 20,31 \\
\hline $\mathbf{5}$ & 4,64 & 5,56 & 19,83 \\
\hline $\mathbf{6}$ & 4,70 & 5,61 & 19,36 \\
\hline $\mathbf{7}$ & 4,54 & 5,46 & 20,26 \\
\hline Média & 4,63 & 5,56 & 20,09 \\
\hline
\end{tabular}

Os materiais apresentaram o mesmo índice de hidratação dos ossos humanos. Ainda, a hidratação é importante para que as células, fibroblastos, interajam com o material.

Granulometria. Para o ensaio de granulometria das amostras, foi realizado um teste em duas amostras distintas. A análise da distribuição granulométrica dos pós cerâmicos foi realizada na Universidade Federal de Minas Gerais por meio do Software Cilas.

Ensaio A: No primeiro ensaio do teste da granulometria, o diâmetro médio das partículas a $90 \%$ de abertura da lente no ensaio de difração é de 10,59 $\mu \mathrm{m}$. Esse resultado foi satisfatório, pois o objetivo era atingir o tamanho mínimo de $10 \mu \mathrm{m}$.

Ensaio B: Foi realizado o teste de granulometria e também do diâmetro médio de partículas. Esse resultado foi satisfatório, pois o objetivo era atingir o tamanho mínimo de $10 \mu \mathrm{m}$.

Citoxicidade. A figura 1 exibe graficamente o resultado dos experimentos de viabilidade celular realizados em laboratório, usando placas Petri contendo fibroblastos humanos e o compósito $\mathrm{Al} 2 \mathrm{O} 3 / \mathrm{ZrO} 2$.

O primeiro experimento, representado na primeira coluna do gráfico, é um comparativo: há a população de células correspondendo $100 \%$ do total. Na segunda, há o cultivo de células em um meio contendo produto iônico (10\% v/v de soro bovino fetal (SBF) (Gibco, EUA)), formando um ambiente propício para o crescimento dos fibroblastos. Na última coluna, o resultado de um meio contendo o produto iônico, os fibroblastos e o compósito. Como pode ser visto, as células conseguiram sobreviver nesse meio e além disso, continuaram a se proliferar. Esse fato mostrou que o compósito deste trabalho não apresentou toxicidade às células fibroblastos humanos, propiciando um ambiente favorável à fixação e ao desenvolvimento das células. Percebe-se, no entanto, que o crescimento das populações de células, comparando-se as colunas do meio e à esquerda, não foi significante (cerca de 17\%), o que torna inconclusivo se o biomaterial incentiva ou não a proliferação de células humanas. 
Com a análise de citotoxidade, na figura 1, conclui-se que as células humanas conseguem viver em um meio contendo o material $\mathrm{Al} 2 \mathrm{O} 3 / \mathrm{ZrO} 2$, o que permite concluir que o compósito possui as características de um biomaterial.

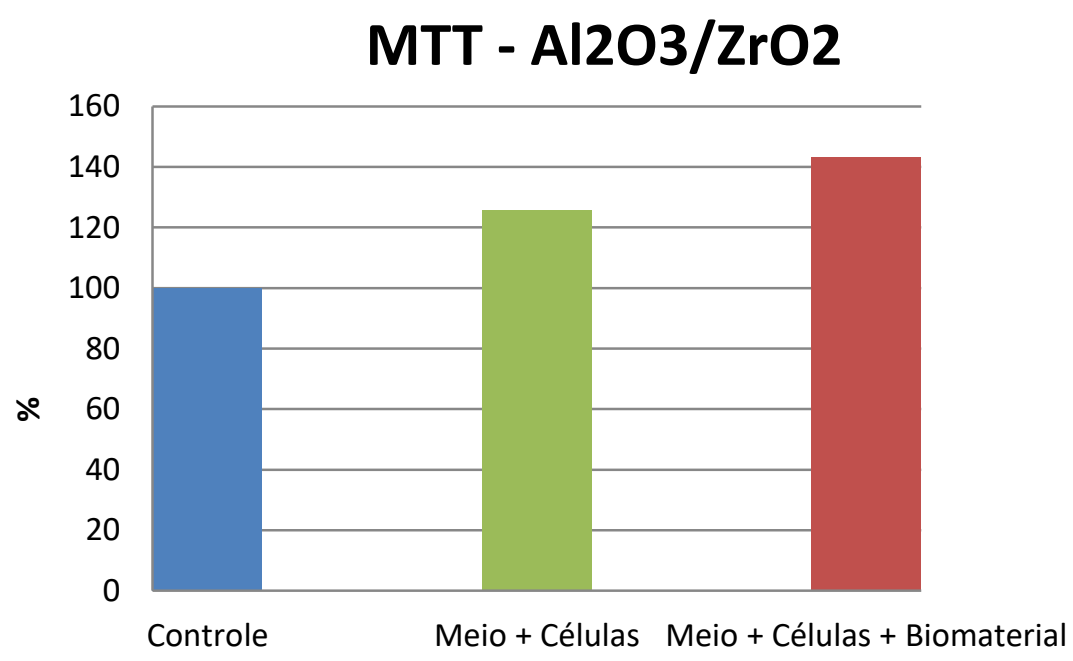

Figura 1: Resultado de Citotoxidade.

Conclusões. Os materiais foram produzidos na PUC-MINAS e alguns testes foram feitos em outras unidades da PUC, como a de Brasília. A caracterização dos materiais indicou boa resistência mecânica e granulometria adequada para implantes que não sofram desgastes e pressão, como os do crânio. Portanto, em termos mecânicos e segundo a metodologia adotada, é possível a produção de próteses com aplicação em substituições ósseas. Os testes de biocompatibilidade mostraram que os materiais produzidos são biocompatíveis e não são tóxicos às células humanas. Isso porque o meio utilizado retrata o meio vivo, como se o teste fosse feito in vivo, estes testes em seres vivos são as direções para futuros trabalhos. Portanto, os materiais obtidos podem ser utilizados em próteses de crânio, por exemplo, a chamada cranioplastia. Finalmente, para testes em seres vivos e para aplicações em seres vivos os implantes devem passar pela Agência Nacional de Vigilância Sanitária, ANVISA.

Declarações. Os autores relatam não haver conflitos de interesse neste trabalho.

\section{References.}

1. BOSCHI OA. O que é necessário para que um material possa ser considerado um biomaterial? Congr Anu da Assoc Bras Metal e Mater. 1995;6:43-53.

2. SAÚDE M DA. MINISTÉRIO DA SAÚDE [Internet]. SISTEMA ÚNICO DE SAÚDE. 2017 [cited 2017 Sep 2]. Available from: https://www.saude.gov.br/sistema-unico-desaude 
3. LANÇA AGH. Estágio atual dos implantes cerâmicos. Universidade Federal de Minas Gerais; 2011.

4. TURRER CL; FERREIRA FPM. Biomateriais em cirurgia craniomaxilofacial: princípios básicos e aplicações. Rev Bras Cir Plast. 2008;23(234-239).

5. SARTORI TAIC. Biocerâmicas porosas de alumina e de alumina-zircônia recobertas com fosfatos de cálcio para implantes ósseos. Faculdade de Zootecnia e Engenharia de Alimentos; 2015.

6. BENETAZZO RAL. Biocerâmicas - desenvolvimento e aplicações. Faculdade de Engenharia Mecânica. Universidade Estadual de Campinas; 2003.

7. SANTOS HES. Propriedades mecânicas da zircônia tetragonal policristalina estabilizada por ítria submetida à degradação hidrotérmica. Instituto Militar de Engenharia; 2012.

8. CHEVALIER J. What future for zirconia as biomaterial. Biomaterials. 2006;27:535-43.

9. HÜBNER H; DORRE E. Alumina. Berlim: Elsevier; 1984.

10. OLIVEIRA MP. Análise in vitro da citotoxicidade e proliferação celular em equivalentes de pele humana. Pontifícia Universidade Católica do Rio Grande do Sul; 2009.

11. FORTULAN CA. Influência dos métodos de injeção e de prensagem isostática no desempenho das cerâmicas estruturais. Universidade de São Paulo; 1997.

12. Gomide VS. Desenvolvimento e caracterização mecânica de hidróxiapatitazircônia, hidróxiapatita-alumina e hi-dróxiapatita-titânia para fins biomédicos. Universidade Estadual de Campinas; 2005. 